\title{
In Vivo Kinetics of Insulin Action on Peripheral Glucose Disposal and Hepatic Glucose Output in Normal and Obese Subjects
}

Rudolf Prager, Penny Wallace, and Jerrold M. Olefsky

Department of Medicine, University of California, San Diego; Veterans Administration Medical Center, San Diego, California 92161

\begin{abstract}
To determine whether abnormal kinetics of insulin's biologic actions contribute to the overall insulin resistance in obesity, we compared the rate of activation and deactivation of insulin's effects to stimulate glucose disposal rate $\left(R_{d}\right)$ and inhibit hepatic glucose output (HGO) in 12 nonobese and 10 obese subjects using the euglycemic clamp technique at insulin infusion rates of $15,40,120$, and $1,200 \mathrm{mU} / \mathrm{M}^{2}$ per min. In both groups, stimulation of $\boldsymbol{R}_{\mathbf{d}}$ was faster the higher the insulin infusion rate and the time to reach half maximal stimulation ( $A_{50}$ value) in normals was $52 \pm 4,44 \pm 2,29 \pm 3$, and $21 \pm 2 \mathrm{~min}$ at infusion rates of 15 , 40,120 , and $1,200 \mathrm{mU} / \mathrm{M}^{2}$ per $\mathrm{min}$, respectively. In the obese subjects, the rate of activation was slower (higher $\mathbf{A}_{\text {so }}$ values) with $A_{50}$ values of $74 \pm 6, P<0.001$ (compared to normal), $64 \pm 8$ $\min , P<0.001$, and $28 \pm 3 \mathrm{~min}, P<0.01$, at the 40, 120, and $1,200 \mathrm{mU} / \mathrm{M}^{2}$ per min insulin infusions. Deactivation of the insulin effect to stimulate glucose disposal rate $\left(\boldsymbol{R}_{\mathrm{d}}\right)$ was faster in the obese group compared with normal individuals after all comparable insulin infusions. In summary: $(a)$ for both groups, the higher the insulin infusion rate, the higher the steady state $\boldsymbol{R}_{\mathrm{d}}$ value, the faster the rate of activation and the slower the subsequent rate of deactivation. (b) In insulin-resistant obese subjects, the rate of activation of insulin action was slower and the rate of deactivation faster at comparable insulin infusion rates. (c) The rate of suppression of HGO was comparable in normal and obese subjects, but the rate of recovery of HGO back to basal values was faster in the obese group. And $(d)$ In view of the phasic manner in which insulin is normally secreted following meals, steady state insulin action is not normally achieved. Therefore, the abnormal kinetics of insulin action in insulinresistant obese individuals may represent functionally important manifestations of the insulin resistance in this condition.
\end{abstract}

\section{Introduction}

The effects of insulin to stimulate glucose disposal are impaired in obesity $(1,2)$, and this is a well-described phenomenon termed insulin resistance. Qualitative estimates of insulin resistance in obesity have been available for a number of years $(3,4)$, but only relatively recently have quantitative assessments become available $(1,2,5)$. These later studies have largely involved measurements of the biologic effectiveness of a given concentration

Address reprint requests to Dr. Olefsky, Veterans Administration Medical Center (111G), 3350 La Jolla Village Drive, San Diego, CA 92161. Dr. Prager is on leave from the Second Department of Medicine, University of Vienna, Austria.

Received for publication 12 November 1985 and in revised form 17 March 1986.

The Journal of Clinical Investigation, Inc.

Volume 78, August 1986, 472-481 of insulin under steady state conditions. For obesity as well as other conditions in which insulin action is impaired (6), in vivo insulin resistance thus is usually defined as a decreased ability of a constant plasma insulin concentration to stimulate overall glucose disposal under steady state conditions where the hormonal effect has plateaued. The glucose clamp technique is an ideal method to achieve these goals and much valuable information has been learned with this approach (7). It takes several hours before steady state biologic effects of constant insulin infusions are reached, however, and this clearly does not reproduce the phasic way in which insulin is delivered into the circulation under physiologic conditions of meal ingestion. Furthermore, assessments confined to steady state measurements of insulin action will not detect kinetic alterations in the onset (activation) or offset (deactivation) of insulin's biologic effects. Indeed, in view of the fact that in response to food, insulin is secreted in a phasic rather than a constant manner, a defect in the dynamics of insulin action might be a physiologically more important manifestation of insulin resistance than reduced steady state hormonal effects.

To evaluate the above ideas, we have used a modification of the euglycemic glucose clamp technique (8) to test the hypothesis that a common human insulin resistant state, i.e., obesity, is characterized by abnormally slow activation and rapid deactivation of insulin's effects to stimulate peripheral glucose uptake. In this report, we show that the kinetics of insulin action are abnormal in obesity and suggest that these kinetic defects represent a physiologically important manifestation of insulin resistance.

\section{Methods}

\section{Materials}

Regular human insulin was supplied by the Eli Lilly Co., Indianapolis, IN. [3- $\left.{ }^{3} \mathrm{H}\right]$ Glucose was purchased from New England Nuclear (Boston, MA).

\section{Subjects}

The study group consisted of 12 lean control subjects and 10 obese subjects. Clinical and metabolic characteristics of the subjects are summarized in Table I. The fasting serum glucose and insulin levels represent the mean of at least three determinations done on consecutive days. All subjects were admitted to the Special Diagnostic and Treatment Unit of the Veterans Administration Medical Center, San Diego. Studies were approved by the Human Subjects Research Review Committee and all subjects gave written informed consent.

\section{Diet}

All subjects were placed on a weight maintaining $(32 \mathrm{kcal} / \mathrm{kg}$ per d) liquid formula diet containing $45 \%$ carbohydrate, $15 \%$ protein, and $40 \%$ fat. The diet was divided into three portions, given at 8:00 a.m., 12:00 a.m., and 5:00 a.m., containing 20,40, and 40\% of the total caloric intake, respectively. All subjects equilibrated on this diet for at least 48 $\mathrm{h}$ before any studies were performed. Each study was carried out on a separate day. 
Table I. Clinical and Metabolic

Characteristics of the Study Groups

\begin{tabular}{lcr}
\hline & Obese & Controls \\
\hline Age $(\mathrm{yr})$ & $43 \pm 13$ & $34 \pm 3$ \\
Height $(\mathrm{cm})$ & $178 \pm 3$ & $174 \pm 3$ \\
Weight $(\mathrm{kg})$ & $116 \pm 9$ & $67 \pm 3$ \\
BMI $\left(\mathrm{kg} / \mathrm{M}^{2}\right)$ & $37 \pm 3$ & $22 \pm 1$ \\
Fasting blood glucose $(\mathrm{mg} / \mathrm{dl})$ & $98 \pm 4$ & $88 \pm 3$ \\
Fasting serum insulin $(\mu \mathrm{U} / \mathrm{ml})$ & $25 \pm 6$ & $11 \pm 3$ \\
Basal HGO (mg/M $\mathbf{M}^{2}$ per $\left.\mathrm{min}\right)$ & $90 \pm 2$ & $82 \pm 3$ \\
\hline
\end{tabular}

Oral glucose tolerance test. All subjects underwent a 75-g oral glucose tolerance test after an overnight fast. Blood was drawn at $0,30,60,90$, 120 , and $180 \mathrm{~min}$ for measurement of glucose and insulin levels.

Glucose clamp studies. A modification of the glucose clamp technique was used to measure the activation and deactivation of in vivo metabolic effects of insulin during a 3-h hormone infusion and during the subsequent deactivation period (8). Clamp studies were started at 7:00 a.m. with the subjects in the postabsorptive state. All infusions were administered through an 8-in. intravenous catheter placed into an antecubital vein. Blood samples were taken from a retrograde cannulated hand vein that was kept in a warming device to insure arterialization of venous blood. After an equilibration period of $60 \mathrm{~min}$, an insulin infusion was started at a constant rate to gradually raise the serum insulin level. Studies were done at four different insulin infusion rates of $15,40,120$, and 1,200 $\mathrm{mU} / \mathrm{M}^{2}$ per min. The plasma glucose level was monitored and maintained between 80 and $90 \mathrm{mg} / \mathrm{dl}$ throughout the study period by infusing $20 \%$ dextrose at a variable rate adjusted according to glucose measurements made at 5-min intervals. A fall in serum potassium and phosphate was prevented by infusion of $\mathrm{K}_{2} \mathrm{PO}_{4}$. The overall rate of glucose disposal was assessed isotopically in 20-min intervals as described below. After $3 \mathrm{~h}$, the insulin infusion was stopped and deactivation of the hormone's effects was assessed. The glucose concentration was kept constant by continuously adjusting the glucose infusion rate and measurements of glucose turnover and serum insulin concentration were continued for 120-180 min following cessation of the insulin infusion. After discontinuation of the $1,200 \mathrm{mU} / \mathrm{M}^{2}$ per min insulin infusion at $3 \mathrm{~h}$, the experiment was stopped without studying deactivation of the hormone effect.

Measurement of glucose turnover. The glucose turnover rate was assessed during the basal state as well as during the activation and deactivation phase of the studies by infusion of $\left[3-{ }^{3} \mathrm{H}\right]$ glucose in a primed continuous manner (an initial bolus of $60 \mu \mathrm{Ci}$ was followed by a continuous infusion rate of $0.6 \mu \mathrm{Ci} / \mathrm{min}$ ). Blood samples were taken at 20 min intervals for determination of glucose concentration and specific activity. Glucose turnover was calculated using the Steele equations in their modified derivative form (9), for non-steady state conditions.

Measurement of hepatic glucose output (HGO). ${ }^{1}$ In the basal state, hepatic glucose production is the only source of glucose entering the system; therefore, the basal glucose appearance rate $\left(R_{\mathrm{a}}\right)$ equals basal hepatic glucose output (HGO). During the insulin infusion (and subsequent deactivation phase), the rate of HGO was calculated as the difference between $R_{\mathrm{a}}$ and the infusion rate of exogenous glucose.

Calculation of incremental glucose disposal rate (IGDR). The activation and deactivation of peripheral glucose disposal was assessed by calculating the incremental glucose disposal rate (IGDR). IGDR was defined as the difference between the basal glucose disposal rate and the measured $R_{\mathrm{d}}$ values during the insulin infusion and subsequent deactivation phase (8).

1. Abbreviations used in this paper: $\mathrm{A}_{50}$, half time activation; $\mathrm{D}_{50}$, half time deactivation; HGO, hepatic glucose output; IGDR, incremental glucose disposal rate; $R_{\mathrm{a}}$, glucose appearance rate; $\boldsymbol{R}_{\mathrm{d}}$, rate of glucose disposal.
Analytical methods

Blood for serum glucose determination was drawn and centrifuged immediately using an Eppendorf microfuge (Brinkmann Instruments, Westbury, NY). Glucose was measured by the glucose oxidase method using an automated glucose analyzer (YSI, model 23A, Yellow Springs Instruments, Yellow Springs, $\mathrm{OH}$ ). Blood for determination of serum insulin was collected in untreated tubes and allowed to clot at room temperature. Blood for glucagon determination was collected into tubes containing Trasylol and allowed to clot at room temperature. After separation all samples were stored at $-20^{\circ} \mathrm{C}$ until analysis. Serum insulin levels were determined by a double antibody radioimmunoassay (10) and serum glucagon was measured by the charcoal separation method of Unger (11).

\section{Data analysis}

Glucose turnover data were calculated using the optimal segments method originally described by Finegood (12). Statistical calculations were performed on the CLINFO system of the Clinical Research Center at the University of California at San Diego Medical Center. Statistical analysis was performed using a two-way analysis of variance adjusted for repeated measures (BMDP 2V Software) and the Student's $t$ test for paired and unpaired data as indicated. Correlation coefficients were calculated using a linear regression analysis.

\section{Results}

Oral glucose tolerance test. Fasting serum glucose levels were $88 \pm 3 \mathrm{mg} / \mathrm{dl}$ and $98 \pm 4 \mathrm{mg} / \mathrm{dl}$ in the nonobese and obese group, respectively. After an oral glucose load of $75 \mathrm{~g}$, six obese and all nonobese subjects had normal glucose tolerance and four obese subjects exhibited impaired glucose tolerance according to the criteria of the National Diabetes Data Group (13). During the glucose tolerance test, serum glucose as well as serum insulin levels were significantly higher in the obese than in the nonobese subjects (Fig. 1).

Serum insulin levels. The serum insulin levels during and after the different insulin infusion rates in nonobese and obese subjects are summarized in Fig. $2 A$ and $B$. Basal insulin levels

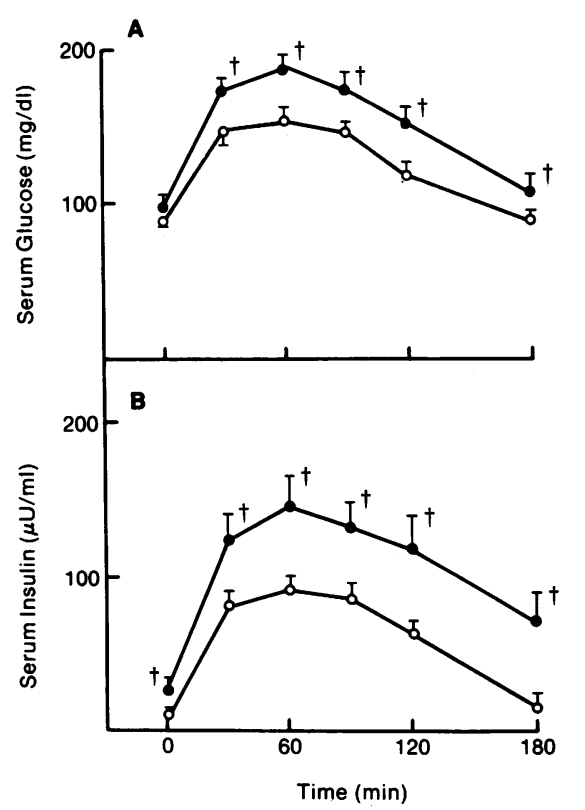

Figure 1. Glucose $(A)$ and insulin levels $(B)$ during the oral glucose tolerance test in normal ( $(0)$ and obese $(\bullet)$ subjects, $\dagger P<0.01$. 


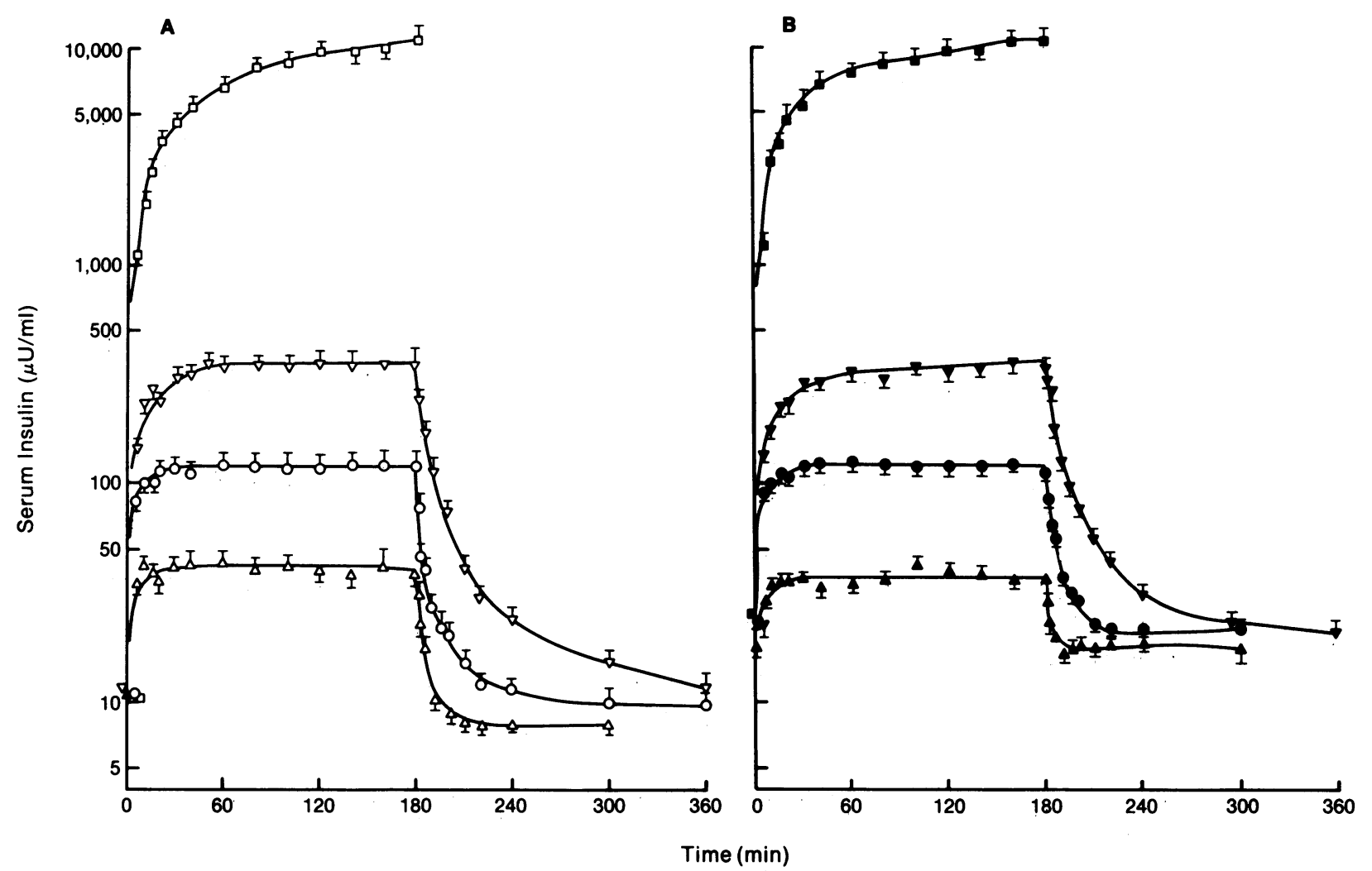

Figure 2. (A) Serum insulin concentrations during and after discontinuation of insulin infusion rates of $15(\triangle), 40(0), 120(\nabla)$, and 1200 (ㅁ) $\mathrm{mU} /$ $\mathbf{M}^{2}$ per min in normal subjects. (B) Serum insulin concentrations during and after discontinuation of insulin infusion rates of $15(\Delta), 40(\bullet), 120$ $(\nabla)$, and 1,200 (ロ) $\mathrm{mU} / \mathrm{M}^{2}$ per $\mathrm{min}$ in obese subjects.

were $11 \pm 3 \mu \mathrm{U} / \mathrm{ml}$ in the nonobese and $25 \pm 6 \mu \mathrm{U} / \mathrm{ml}$ in the obese subjects $(P<0.01)$. At corresponding insulin infusion rates of $15,40,120$, and $1,200 \mathrm{mU} / \mathrm{M}^{2}$ per min, steady state insulin levels were not significantly different between obese and nonobese subjects. During the insulin infusion rates of 15,40 , and $120 \mathrm{mU} / \mathrm{M}^{2}$ per min the $t_{1 / 2}$ values to approach steady state, were the same in both groups; $3 \pm 1,3 \pm 1$, and $8 \pm 2 \mathrm{~min}$ in the obese and $3 \pm 1,3 \pm 1$, and $8 \pm 2$ in the nonobese subjects, respectively. Similarly, the $t_{1 / 2}$ values of the serum insulin decay curves, after termination of the insulin infusions, were $3 \pm 1,3 \pm 2$, and $7 \pm 2 \mathrm{~min}$ in the obese and $3 \pm 1,3 \pm 2,7 \pm 2$ in the nonobese subjects, respectively. During the $1,200-\mathrm{mU} / \mathrm{M}^{2}$ per min infusion, the approach to steady state insulin levels was prolonged $\left(t_{1 / 2}\right.$ $>35 \mathrm{~min}$ ) for both groups, with plasma levels still rising at 180 min; deactivation studies were not performed after the 1,200$\mathrm{mU} / \mathrm{M}^{2}$ per min insulin infusion. The higher $\mathrm{t}_{1 / 2}$ values at the higher infusion rates indicate saturation of the insulin removal mechanisms and this effect was comparable in both groups. At identical constant insulin infusion rates, steady state insulin levels, as well as the pharmacokinetics of insulin appearance and disappearance thus were the same in normal and obese subjects.

Steady-state glucose disposal rates. In the nonobese subjects, steady state $R_{\mathrm{d}}$ levels of $168 \pm 10,268 \pm 20,342 \pm 25$, and $422 \pm 22$ $\mathrm{mg} / \mathrm{M}^{2}$ per min, were achieved with the $15-, 40-, 120$-, and $1,200-$ $\mathrm{mU} / \mathrm{M}^{2}$ per min insulin infusions, respectively (Fig. $3 A$ ). In the obese group, steady state $R_{\mathrm{d}}$ values were $93 \pm 5$ (NS compared with basal $R_{\mathrm{d}}$ ), $152 \pm 9,250 \pm 7$, and $300 \pm 10 \mathrm{mg} / \mathrm{M}^{2}$ per min during the 15-, 40-, 120-, and 1,200-mU/ $\mathrm{M}^{2}$ per min insulin infusions, respectively. Steady state $R_{\mathrm{d}}$ thus was significantly re- duced at all insulin levels in the obese subjects $(P<0.001)$, demonstrating the insulin resistance characteristic of obesity $(1,2)$.

Rate of stimulation (activation) of glucose disposal rates. In the control subjects, absolute rates of activation of insulin-stimulated glucose disposal (calculated as initial slopes of the activation curves, Fig. 3 ) were $0.8 \pm 0.05$ (mean $\pm \mathrm{SE}$ ), $2.02 \pm 0.24$, $3.18 \pm 0.41$, and $8.1 \pm 1.1 \mathrm{mg} / \mathrm{min}$, respectively, at insulin infusion rates of $15,40,120$, and $1,200 \mathrm{mU} / \mathrm{M}^{2}$ per min. In the obese the activation rates were $\sim 0,0.46 \pm 0.06,1.29 \pm 0.14$, and $3.43 \pm 0.29 \mathrm{mg} / \mathrm{min}$, respectively, at insulin infusion rates of 15 , 40,120 , and $1,200 \mathrm{mU} / \mathrm{M}^{2}$ per min. The rate of activation increased in both the controls and the obese subjects with increasing insulin infusion rates and increasing steady state $R_{d}$ values. However, for any given insulin concentration, the rate of activation of $R_{\mathrm{d}}$ was significantly reduced in the obese individuals compared with the control individuals $(P<0.001)$.

The absolute slopes calculated from the $R_{d}$ data in Fig. 3 represent the absolute rates of activation and the decreased rates observed in the obese group are at least partially due to the reduced steady state $\boldsymbol{R}_{\mathrm{d}}$ values. To compare activation kinetics independent of the ultimate steady state glucose disposal values, it is the fractional (or relative) rate of activation that is of most interest. To estimate this rate, we calculated the apparent half times of the insulin-mediated rise from basal $R_{\mathrm{d}}$ to steady state $R_{\mathrm{d}}$ and the subsequent deactivation back to the basal value. The difference between basal and stimulated glucose disposal rate is termed the incremental glucose disposal rate, and the apparent half time values are designated $A_{50}$ IGDR and $D_{50}$ IGDR, for 

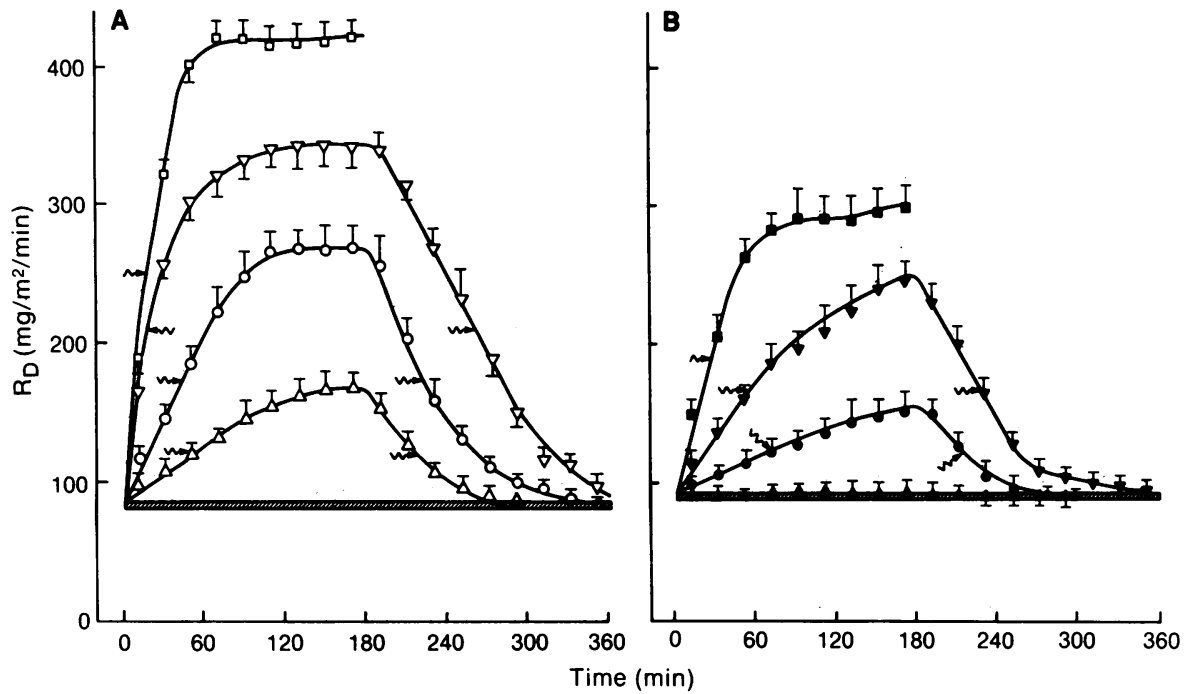

Figure 3. (A) Time course of total $R_{\mathrm{d}}$ during and after termination of insulin infusion rates of $15(\Delta), 40(0), 120(\nabla)$, and $1,200(\square) \mathrm{mU} / \mathrm{M}^{2}$ per min in normal subjects. (B) Time course of $R_{\mathrm{d}}$ during and after termination of insulin infusion rates of $15(\triangle), 40(\bullet), 120(\nabla)$, and $1,200(\bullet)$ $\mathrm{mU} / \mathrm{M}^{2}$ per $\mathrm{min}$ in obese subjects.

activation and deactivation kinetics, respectively. Since in vivo activation and deactivation of glucose disposal is a complex multistepped phenomenon, the apparent half times are used as kinetic measures in lieu of rate constants. These values can be calculated from the absolute $R_{\mathrm{d}}$ data in Fig. 3 (as indicated by the arrows), but are more readily appreciated by expressing the IGDR data as a percentage of the maximal IGDR value, at each

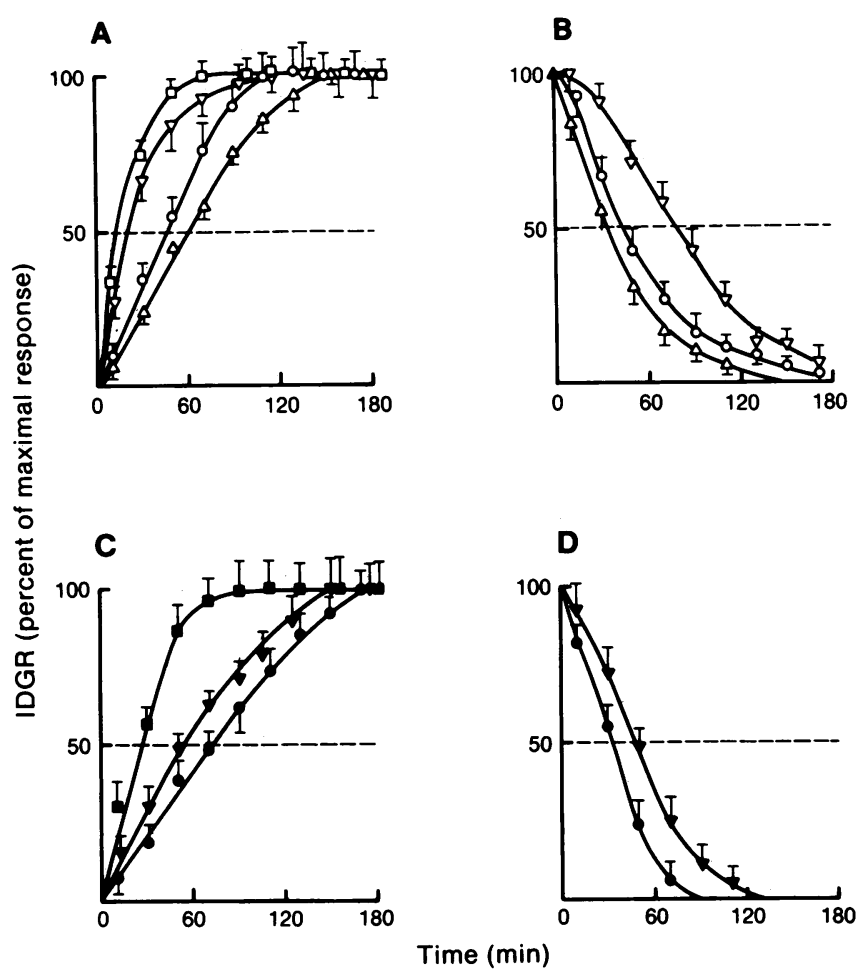

Figure 4. Time course of activation (A, C) and deactivation (B, D) of IGDR. Data are expressed as a percentage of the maximal response, observed at the end of the infusion, and IGDR is defined as the difference between the initial basal $R_{\mathrm{d}}$ value and the $R_{\mathrm{d}}$ values during and after cessation of the insulin infusion. Controls at insulin infusion rates of $15(\Delta), 40(0), 120(\nabla)$, and $1,200(\square) \mathrm{mU} / \mathrm{M}^{2}$ per min. Obese subjects at insulin infusion rates of $40(\bullet), 120(\nabla)$, and $1,200(\bullet) \mathrm{mU} /$ $\mathrm{U}^{2}$ per min. insulin infusion. This analysis is presented in Fig. 4 for both groups.

The fractional rate of activation of insulin's effect to stimulate glucose disposal increased progressively with increasing insulin infusion rate. In the normal subjects, the $A_{50}$ IGDR values were $52 \pm 4,44 \pm 2,29 \pm 3$, and $21 \pm 2 \mathrm{~min}$ at insulin infusion rates of $15,40,120$, and $1,200 \mathrm{mU} / \mathrm{M}^{2}$ per min (Fig. $4 A$ and Table II). An increase in the insulin infusion rate thus led to higher steady state insulin levels, higher IGDR values, and lower $A_{50}$ IGDR values (faster activation). An identical trend was observed in the obese subjects (Fig. $4 \mathrm{C}$ ). The $\mathrm{A}_{50}$ IGDR values were $74 \pm 6$, $64 \pm 8$, and $28 \pm 3 \mathrm{~min}$ at the 40,120 , and $1,200 \mathrm{mU} / \mathrm{M}^{2}$ per min insulin infusion studies, respectively, (at $15 \mathrm{mU} / \mathrm{M}^{2}$ per min, the increase in $R_{\mathrm{d}}$ was negligible in the obese subjects precluding estimation of either activation or deactivation values).

Although the phenomenon of increasing activation rates at higher insulin infusion rates was observed in both groups, marked differences in $A_{50}$ IGDR values existed when the normal and obese subjects were compared (Table II). When comparing the groups at the same insulin infusion rates, activation values were $44 \pm 2$ vs. $74 \pm 6 \min (P<0.001)$ during the $40-\mathrm{mU} / \mathrm{M}^{2}$ per $\min$ study, $29 \pm 3$ vs. $64 \pm 8 \mathrm{~min}(P<0.001)$, during the $120-\mathrm{mU} / \mathrm{M}^{2}$ per min study, and $21 \pm 2$ vs. $28 \pm 3(P<0.01)$ during the 1,200 $\mathrm{mU} / \mathrm{M}^{2}$ per min study, in the normal vs. obese subjects, respectively.

Table II. Half Maximal Activation $\left(A_{50} I G D R\right)$ and Deactivation $\left(D_{s 0} I G D R\right)$ Values in Normal and Obese Subjects

\begin{tabular}{|c|c|c|c|c|}
\hline \multirow[b]{2}{*}{ Insulin infusion rate } & \multicolumn{2}{|c|}{$\mathrm{A}_{\mathbf{s o}}$ IGDR } & \multicolumn{2}{|c|}{$D_{s 0}$ IGDR } \\
\hline & Normal & Obese & Normal & Obese \\
\hline & $\min$ & $\min$ & $\min$ & $\min$ \\
\hline $15 \mathrm{mU} / \mathrm{M}^{2}$ per min & $52 \pm 4$ & - & $34 \pm 3$ & - \\
\hline $40 \mathrm{mU} / \mathrm{M}^{2}$ per $\min$ & $44 \pm 2$ & $74 \pm 6 \ddagger$ & $43 \pm 2$ & $31 \pm 6^{*}$ \\
\hline $120 \mathrm{mU} / \mathrm{M}^{2}$ per min & $29 \pm 3$ & $64 \pm 8 \ddagger$ & $78 \pm 5$ & $46 \pm 2 *$ \\
\hline $1,200 \mathrm{mU} / \mathrm{M}^{2}$ per $\min$ & $21 \pm 2$ & $28 \pm 3^{*}$ & & \\
\hline
\end{tabular}

${ }^{*} P<0.01$

$\ddagger P<0.001$; obese vs. nonobese. 
However, at the same insulin infusion rates, the steady state $R_{\mathrm{d}}$ values were all significantly lower in the obese subjects (compare Fig. $3 A$ and $B$ ). Therefore, we compared the rate of stimulation of glucose disposal between the two groups at similar steady state GDR, but at different insulin infusion rates. Fig. 5 $A$ presents the time course curves for the normal subjects at an insulin infusion of $15 \mathrm{mU} / \mathrm{M}^{2}$ per min vs. the obese at $40 \mathrm{mU} /$ $\mathrm{M}^{2}$ per min and Fig. $5 \mathrm{~B}$ compares the results in normal individuals at $40 \mathrm{mU} / \mathrm{M}^{2}$ per min to the obese subjects at $120 \mathrm{mU} /$ $\mathrm{M}^{2}$ per min. As can be seen, even at comparable ultimate $R_{\mathrm{d}}$ values, the activation rates are still significantly slower in obese compared to normal subjects ( $A_{50}$ IGDR of $52 \pm 4$ vs. $74 \pm 6 \mathrm{~min}$, $P<0.01$, for normal subjects at $15 \mathrm{mU} / \mathrm{M}^{2}$ per min and obese at $40 \mathrm{mU} / \mathrm{M}^{2}$ per min, and $44 \pm 2$ vs. $64 \pm 8 \mathrm{~min}, P<0.01$, for normal subjects at $40 \mathrm{mU} / \mathrm{M}^{2}$ per min and obese subjects at $120 \mathrm{mU} / \mathrm{M}^{2}$ per min). Inspection of Fig. $5 A$ raises the possibility that $\boldsymbol{R}_{\mathrm{d}}$ might have continued to rise in the obese group after $180 \mathrm{~min}$, such that the steady state $R_{\mathrm{d}}$ value would be slightly higher than the 180 -min value. Although this may or may not have occurred, it should be noted that insofar as $R_{\mathrm{d}}$ would continue to rise in the obese group, the $\mathrm{A}_{50}$ value would also increase; therefore, the $\mathrm{A}_{50}$ values obtained from Fig. $5 \mathrm{~A}$, if anything, underestimate the differences in the rate of insulin action between the two groups. Furthermore, at the maximal insulin infusion rate $\left(1,200 \mathrm{mU} / \mathrm{M}^{2}\right.$ per min), pharmacologic insulin levels are achieved very rapidly (by $1 \mathrm{~min}$ ), and even at these insulin values, activation of glucose disposal was significantly slower in the obese group ( $21 \pm 2$ vs. $28 \pm 3 \mathrm{~min}, P<0.01$ ). In aggregate, these results

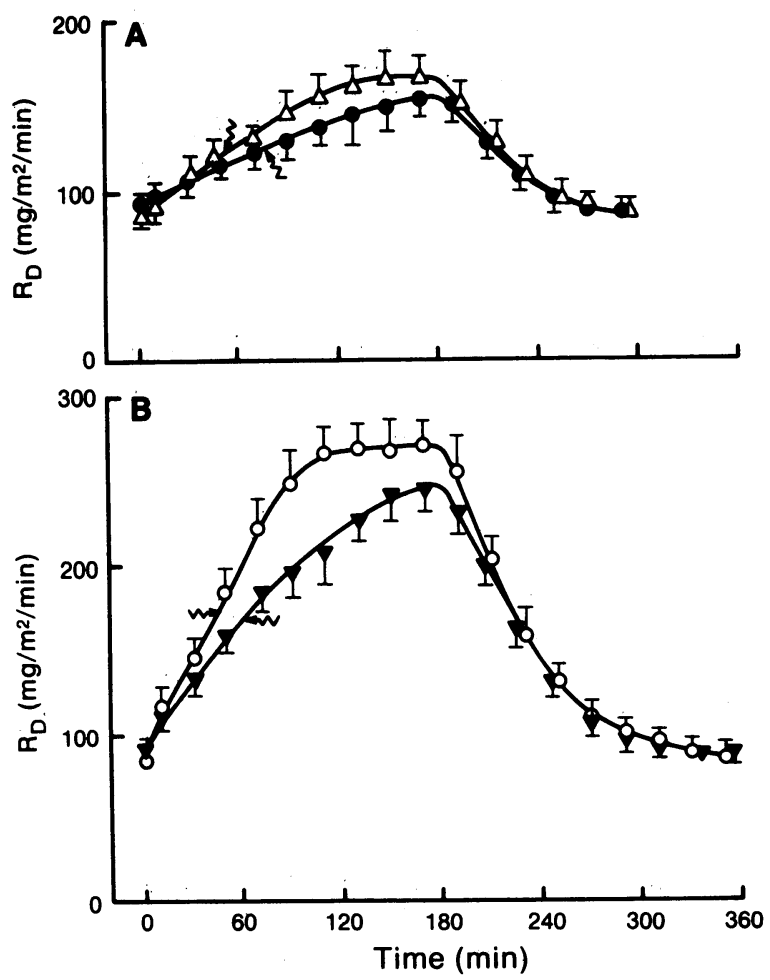

Figure 5. (A) Activation and deactivation of $R_{\mathrm{d}}$ at the $15-\mathrm{mU} / \mathrm{M}^{2}$ per min insulin infusion in normals $(\Delta)$ compared to the $40-\mathrm{mU} / \mathrm{M}^{2}$ per min insulin infusion in the obese subjects $(\bullet)$. (B) Activation and deactivation of $R_{\mathrm{d}}$ at the $40-\mathrm{mU} / \mathrm{M}^{2}$ per min insulin infusion in normals (o) compared with the $120-\mathrm{mU} / \mathrm{M}^{2}$ per min insulin infusion in the obese subjects ( $\mathbf{\nabla})$. demonstrate that the rate at which insulin stimulates overall in vivo glucose uptake is slower in obesity and indicate that these differences are not due to differences in pharmacokinetics of insulin in plasma or its access to tissue sites of action.

Deactivation of insulin stimulation of glucose disposal. The deactivation curves were linearized by $\log$ transformation and the absolute rate of deactivation (i.e., slope) was calculated. In contrast to the rates of activation, absolute rates (slopes) of deactivation were found to be similar at all insulin concentrations in the normals and the obese subjects. The calculated slopes were $-0.33 \pm 0.11,-0.46 \pm 0.13$, and $-0.32 \pm 0.06 \times 10^{-2}$ in the control subjects at insulin infusion rates of 15,40 , and $120 \mathrm{mU} /$ $\mathrm{M}^{2}$ per min, vs. $-0.30 \pm 0.12$ and $-0.43 \pm 0.09 \times 10^{-2}$ in the obese subjects at insulin infusion rates of 40 and $120 \mathrm{mU} / \mathrm{M}^{2}$ per min. However, since steady state $R_{\mathrm{d}}$ and IGDR values were significantly higher the greater the insulin infusion rate, in view of similar absolute slopes of the deactivation curves, it follows that the fractional or relative rate, as estimated by the half time of deactivation ( $D_{50}$ IGDR) of insulin's effect to stimulate glucose disposal, decreased progressively with increasing insulin infusion rates in both groups (Fig. 4, Table II). As seen in Fig. $4 C$ and Table II, in the normal subjects, the $D_{50}$ IGDR values were $34 \pm 3,43 \pm 2$, and $78 \pm 5$ at insulin infusion rates of 15,40 , and $120 \mathrm{mU} / \mathrm{M}^{2}$ per min, respectively (because of the markedly prolonged clearance of the pharmacologic insulin levels reached during the $1,200-\mathrm{mU} / \mathrm{M}^{2}$ per min infusion, deactivation phases were not carried out after these studies). Increasing the insulin infusion rate thus led to higher steady state insulin and $R_{\mathrm{d}}$ levels, but progressively higher $\mathrm{D}_{50}$ IGDR values (slower deactivation). The same trend was observed in the obese subjects; the $D_{50}$ IGDR values were $31 \pm 6$ and $46 \pm 2$ during the 40 - and 120 -mU/M ${ }^{2}$ per min studies, respectively (Fig. $4 \mathrm{D}$ ). As mentioned earlier, deactivation values were not measured during the $15-\mathrm{mU} / \mathrm{M}^{2}$ per min study since stimulation of $R_{\mathrm{d}}$ in the obese group was negligible (Fig. $3 B$ ).

The relationship between decreasing rates of deactivation with higher IGDR values was noted in both groups, but striking differences in $D_{50}$ IGDR values were observed between the groups when comparisons were made at comparable insulin infusion rates (Fig. 4, Table II). When comparing deactivation rates at the same insulin infusion rates, the $D_{50}$ IGDR values were $43 \pm 2$ vs. $31 \pm 6 \mathrm{~min}(P<0.01)$ after the $40-\mathrm{mU} / \mathrm{M}^{2}$ per min infusion and $78 \pm 5$ vs. $46 \pm 2(P<0.01)$ after the $120-\mathrm{mU} /$ $\mathbf{M}^{2}$ per min infusion in the normal and obese subjects, respectively. The rate of deactivation of insulin action thus was faster in the insulin-resistant obese subjects after the same steady state insulin infusion study. However, as discussed above, the steady state glucose disposal rates were always lower in the obese groups compared to normals at the same insulin infusion rate. We also compared the rates of deactivation between the two groups, therefore, after achieving comparable glucose disposal rates, but at different insulin infusion rates. As seen in Fig. 5, the steady state $R_{\mathrm{d}}$ values in normals were $168 \pm 10$ and $268 \pm 20 \mathrm{mg} / \mathrm{M}^{2}$ per min, respectively, during the $15-$ and $40-\mathrm{mU}$ insulin infusions, indistinguishable from the values of $152 \pm 9$ and $250 \pm 7$ $\mathrm{mg} / \mathrm{M}^{2}$ per $\mathrm{min}$ in the obese group at insulin infusions of 40 and $120 \mathrm{mU} / \mathrm{M}^{2}$ per min. As Fig. $5 A$ and $B$ shows, the rates of deactivation were not different between the groups following the 15-mU (normal) and 40-mU (obese) insulin infusion ( $D_{50}$ IGDR values of $34 \pm 3$ and $31 \pm 6 \mathrm{~min}, \mathrm{NS}$ ), or following the $40-\mathrm{mU}$ (normal) and 120-mU (obese) insulin infusion $\left(D_{50}\right.$ IGDR values 
of $43 \pm 2$ and $46 \pm 2 \mathrm{~min}, \mathrm{NS})$. After similar steady state glucose disposal rates were achieved, although at different insulin infusion rates, the rates of deactivation of insulin-stimulated glucose disposal thus were quite comparable in normal compared with insulin-resistant obese subjects.

Effect of insulin to suppress HGO. Steady state suppression of $\mathrm{HGO}$ was complete ( $100 \%$ suppression) in the normal subjects at insulin infusion rates of $40 \mathrm{mU} / \mathrm{M}^{2}$ per min and higher (Fig. $6 B$ and $C$ ), and HGO was $90 \%$ suppressed at the end of the 15 $\mathrm{mU} / \mathrm{M}^{2}$ per min infusion (Fig. $6 \mathrm{~A}$ ). In contrast, $\mathrm{HGO}$ was only $\sim 80 \%$ suppressed in the obese group $(P<0.05$ compared with control) during the 15 (Fig. $6 \mathrm{~A}$ ) and $40 \mathrm{mU} / \mathrm{M}^{2}$ per min (Fig. $6 B$ ) infusions, but was completely suppressed at the higher insulin infusion rates. Under steady state conditions, the liver thus is less sensitive to the suppressive effects of physiologic insulin concentrations on HGO in obesity, indicating resistance to this hepatic action of insulin. In theory, HGO cannot be more than $100 \%$ suppressed, but occasional slightly negative values were observed at high rates of $R_{\mathrm{d}}$ (Fig. 6). This has also been reported by other groups, and although the negative values are quantitatively small, the reason for this remains unclear.

Insulin acted more rapidly to suppress HGO than it did to stimulate glucose disposal at all insulin levels in both groups. There was a trend toward faster rates of suppression the higher the insulin infusion rate (Fig. 6, Table III), but importantly, no difference existed between the rate of suppression of HGO at
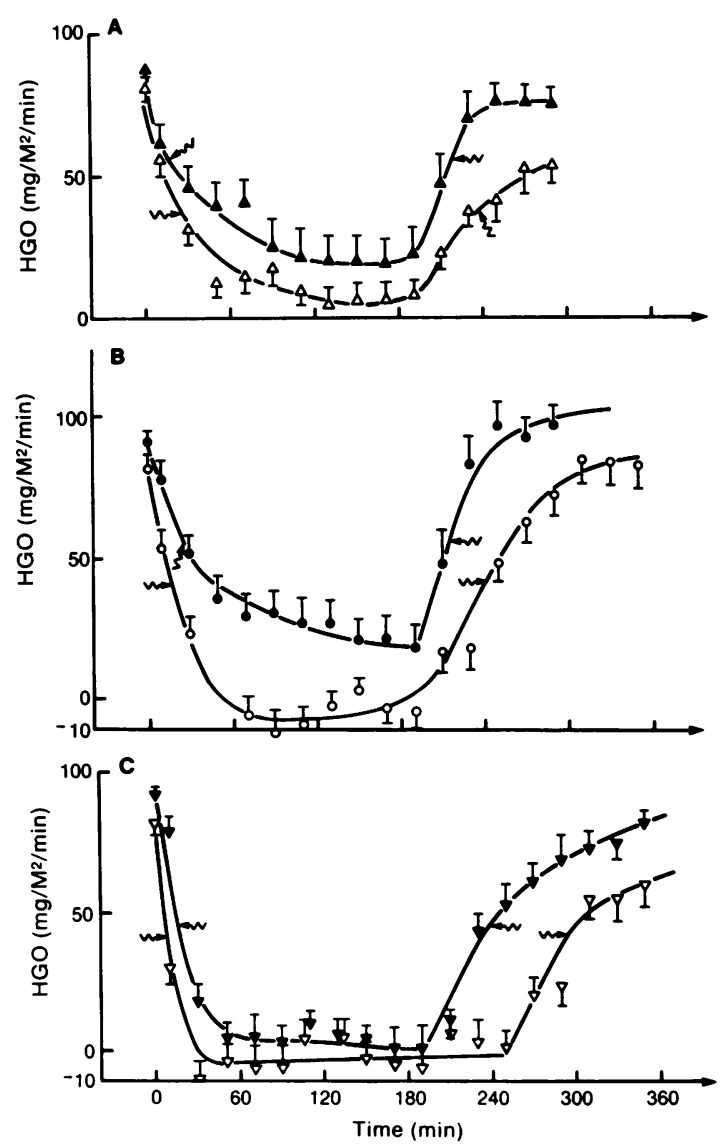

Figure 6. Time course of suppression and recovery of $\mathrm{HGO}$ at insulin infusion rates of $15(A), 40(B)$, and $120(C) \mathrm{mU} / \mathrm{M}^{2}$ per min in normal (open symbols) and obese (closed symbols) subjects. any insulin infusion between the normal and obese groups. HGO was completely suppressed in both groups within $15 \mathrm{~min}$ at the highest insulin infusion $\left(1,200 \mathrm{mU} / \mathrm{M}^{2}\right.$ per min) rate (data not shown).

Rate of recovery of $H G O$ from insulin suppression. Following cessation of the insulin infusions, the recovery of HGO was far more rapid in the obese compared with the control group (Fig. 6 ). The half time for recovery of HGO (calculated as the time at which HGO increased by $50 \%$ of the absolute amount of suppression achieved at steady state) thus was $35 \pm 6$ vs. $54 \pm 2$ $\min (P<0.01)$ for the obese and normal groups, respectively, after the $15-\mathrm{mU} / \mathrm{M}^{2}$ per min infusion (Fig. $6 \mathrm{~A}$ ). Following the 40- (Fig. $6 \mathrm{~B}$ ) and 120 -mU/M ${ }^{2}$ per min (Fig. $6 \mathrm{C}$ ) infusions the corresponding half time recovery values were $35 \pm 8$ vs. $59 \pm 8$ min, $P<0.01$, and $59 \pm 8$ vs. $119 \pm 6 \min (P<0.01)$ for the obese and control groups, respectively. Following comparable steady state insulin infusion rates, recovery from insulin's suppressive effects on HGO thus was more rapid in the insulinresistant obese group. It should be noted that the degree of suppression of HGO was less in the obese group compared with control at the $15-$ and $40-\mathrm{mU} / \mathrm{M}^{2}$ per min insulin infusions. As discussed earlier, deactivation studies were not conducted after the $1,200-\mathrm{mU} / \mathrm{M}^{2}$ per min infusions.

Effect of insulin on serum glucagon levels. Basal glucagon values were $165 \pm 22 \mathrm{pg} / \mathrm{ml}$ in the obese group and $118 \pm 6 \mathrm{pg} /$ $\mathrm{ml}$ in the control subjects $(P<0.01)$. During all insulin infusions, glucagon levels suppressed comparably $(25-35 \%, P<0.001)$ by $180 \mathrm{~min}$ in the control subjects (Fig. $7 A$ ) and following discontinuation of the insulin infusion, glucagon values remained suppressed for up to 180 additional minutes relative to the basal values. In the obese group (Fig. $7 \mathrm{~B}$ ), glucagon levels did not change significantly at any time point during the $15-\mathrm{mU}$ infusion. During the 40-mU study, glucagon levels were significantly suppressed by 15 and $17 \%(P<0.05)$ at 120 and $180 \mathrm{~min}$, respectively, and this degree of suppression was less $(P<0.05)$ compared to the normal subjects at the same insulin infusion rate; glucagon levels rapidly returned to baseline values following cessation of the 40-mU insulin infusion. During the higher dose insulin infusions, glucagon suppression was comparable in the obese and normal groups, but recovered toward baseline more rapidly (i.e., $120 \mathrm{mU} / \mathrm{M}^{2}$ per min insulin infusion) in the obese subjects.

Correlation between steady state glucose disposal and rates of activation and deactivation. In individual obese and control subjects, the negative correlation between steady state IGDR

Table III. Half Maximal Suppression ( $\left.A_{50} H G O\right)$ and Half Maximal Recovery $\left(D_{50} H G O\right)$ of HGO in Normal and Obese Subjects

\begin{tabular}{|c|c|c|c|c|}
\hline \multirow[b]{2}{*}{ Insulin infusion rate } & \multicolumn{2}{|c|}{$\mathrm{A}_{\text {so }} \mathrm{HGO}$} & \multicolumn{2}{|c|}{$\mathrm{D}_{s 0} \mathrm{HGO}$} \\
\hline & Normal & Obese & Normal & Obese \\
\hline & $\min$ & $\min$ & $\min$ & $\min$ \\
\hline $15 \mathrm{mU} / \mathrm{M}^{2}$ per $\min$ & $22 \pm 3$ & $21 \pm 4$ & $54 \pm 2$ & $35 \pm 6^{*}$ \\
\hline $40 \mathrm{mU} / \mathrm{M}^{2}$ per min & $18 \pm 6$ & $23 \pm 5$ & $59 \pm 8$ & $35 \pm 8^{*}$ \\
\hline $120 \mathrm{mU} / \mathrm{M}^{2}$ per $\min$ & $11 \pm 3$ & $15 \pm 4$ & $119 \pm 6$ & $59 \pm 8^{*}$ \\
\hline $1,200 \mathrm{mU} / \mathrm{M}^{2}$ per $\min$ & $12 \pm 3$ & $14 \pm 2$ & - & - \\
\hline
\end{tabular}

${ }^{*} P<0.01$, obese vs. nonobese. 


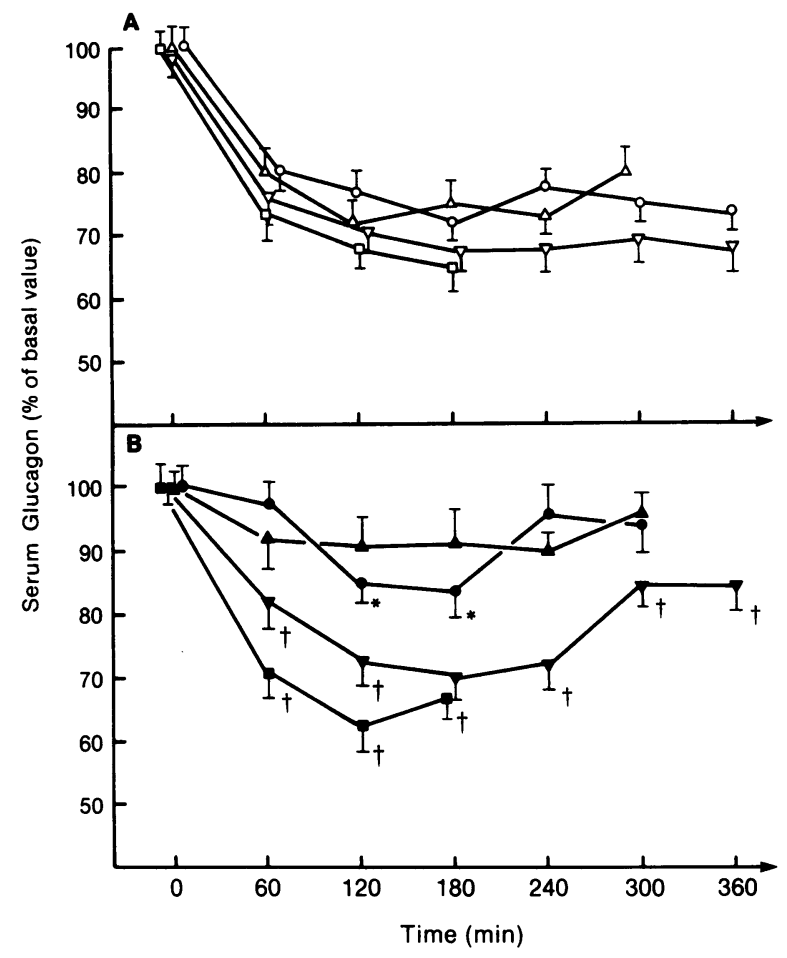

Figure 7. (A) Time course of suppression and recovery of plasma glucagon levels at insulin infusion rates of $15(\triangle), 40(0), 120(\nabla)$, and $1,200(\square) \mathrm{mU} / \mathrm{M}^{2}$ per min in normal subjects. All data points are significantly different $(P<0.01)$ from the basal glucagon value of $118 \pm 6$ $\mathrm{pg} / \mathrm{ml}$. (B) Time course of suppression and recovery of plasma glucagon levels at insulin infusion rates of $15(\Delta), 40(\bullet), 120(\nabla)$, and 1,200 (a) $\mathrm{mU} / \mathrm{M}^{2}$ per $\mathrm{min}$ in the obese subjects. ${ }^{*} P<0.05$; $† P<0.01 \mathrm{com}$ pared to the basal glucagon value of $165 \pm 22 \mathrm{pg} / \mathrm{ml}$.

and the fractional rate of activation ( $\mathrm{A}_{50}$ IGDR) was highly significant $(r=-0.63, P<0.001$ in the obese and $r=-0.72, P$ $<0.001$ in the controls). The correlation between these two variables for both groups combined was $-0.74(P<0.001)$. Thus, even among individual subjects and within groups, the greater the ultimate insulin effect (higher steady state IGDR) the more rapidly insulin activates the glucose disposal system (lower $\mathrm{A}_{50}$ IGDR values). The height of the individual IGDR values was also correlated to the fractional rate of deactivation $(r=0.65$, $P<0.001)$ in obese and nonobese combined. The lower the IGDR value, the more rapidly deactivation occurred.

\section{Discussion}

Insulin resistance is a characteristic feature of obesity (1-6), as well as other common pathophysiologic states such as noninsulin-dependent diabetes (14-17). Most in vivo methods for quantitating insulin resistance rely upon measurements of insulin's ability to promote glucose disposal during constant intravenous infusion under steady state, or near steady state conditions. While these types of studies have yielded a great deal of valuable information, it takes several hours for the biologic effects of insulin on in vivo glucose disposal to plateau and reach steady state values. Since this is not representative of the manner in which insulin is secreted in response to food ingestion, steady state measures of insulin's effects will not detect kinetic defects in insulin action. Indeed, except under basal conditions where insulin-mediated glucose uptake is minimal (18), given the relatively rapid rise and fall in plasma insulin after meals, it is highly unlikely that steady state biologic effects of insulin are ever achieved in the physiologic state. If kinetic defects in the rate of onset and/or deactivation of insulin action exist, such defects thus might be of physiologic importance. The current studies demonstrate that in insulin-resistant obese subjects, the rate of activation of insulin's effects on glucose disposal is slower and the rate of deactivation of these effects faster than in normals. It is suggested that these kinetic abnormalities of insulin action may be a functionally more important aspect of insulin resistance under physiologic meal eating conditions than the reduced steady state biologic effects of insulin that have been previously described $(1,2,5)$.

In the current group of obese subjects the steady state effects of insulin to stimulate overall glucose disposal are decreased at all insulin concentrations. The magnitude of the decrease is greater the lower the insulin concentration. Essentially no stimulation of glucose disposal thus was observed in the obese group at the lowest insulin infusion rate $\left(15 \mathrm{mU} / \mathrm{M}^{2}\right.$ per $\left.\mathrm{min}\right)$, which produced mean insulin levels of $\sim 45 \mu \mathrm{U} / \mathrm{ml}$, and compared with controls, the decrease in insulin-stimulated glucose disposal was 44,27 , and $28 \%$ at insulin levels of $\sim 100,300$, and 10,000 $\mu \mathrm{U} / \mathrm{ml}$, respectively. The greater impairment of insulin action at the lower insulin levels indicates decreased insulin sensitivity (19), and the decreased glucose disposal at maximal insulin levels demonstrates decreased insulin responsiveness (19).

In addition to these steady state manifestations of insulin resistance, marked kinetic abnormalities of insulin action were also observed. In normal subjects, the rate of activation of insulin's stimulatory effects on glucose disposal increased the higher the insulin infusion rate (and higher the $R_{\mathrm{d}}$ ). At the lowest insulin infusion rate $\left(15 \mathrm{mU} / \mathrm{M}^{2}\right.$ per min, insulin level $\left.\sim 45 \mu \mathrm{U} / \mathrm{ml}\right)$ the steady state $R_{\mathrm{d}}$ was $168 \pm 10 \mathrm{mg} / \mathrm{kg}$ per min and the half time $\left(\mathrm{A}_{50} \mathrm{IGDR}\right.$ ) to achieve this value was $52 \pm 4 \mathrm{~min}$; at the highest insulin infusion rate $\left(1,200 \mathrm{mU} / \mathrm{M}^{2}\right.$ per min, plasma insulin $\sim 10,000 \mu \mathrm{U} / \mathrm{ml}$ ) the steady state $R_{\mathrm{d}}$ value was $422 \mathrm{mg} / \mathrm{M}^{2}$ per min and the half time to reach this value was only $21 \pm 2 \mathrm{~min}$. Therefore, as the insulin concentration increases, not only does the $R_{\mathrm{d}}$ rise, but so does the effect of insulin to accelerate the cellular processes that govern the fractional rate of rise in glucose disposal. ${ }^{2}$ A similar phenomenon was seen in the obese subjects. The higher the insulin infusion, the faster the activation rate for stimulation of glucose disposal; the $A_{50}$ IGDR values was $74 \pm 6$ $\mathrm{min}$ at $\sim 100 \mu \mathrm{U} / \mathrm{ml}$ (40 $\mathrm{mU}$ infusion) and $28 \pm 3 \mathrm{~min}$ at $\sim 10,000 \mu \mathrm{U} / \mathrm{ml}$ (1,200 mU infusion). However, at each insulin infusion rate the $A_{50}$ IGDR values were significantly lower in obesity, indicating a decrease in the rate of activation of insulin action. On the other hand, since activation was faster the higher the $R_{\mathrm{d}}$ in either group, it seemed possible that the slower rate insulin action in obesity was a reflection of the decreased steady state effects of insulin to stimulate $R_{\mathrm{d}}$. To assess this possibility we compared the rates of activation at similar levels of glucose

2. It should be noted that this relationship refers to the steady state $R_{\mathrm{d}}$ values and the fractional (or relative) rates as assessed by $A_{50}$ values. The relationship is even stronger if absolute rates of activation (as calculated from the slopes of the absolute $R_{\mathrm{d}}$ values in Fig. 3) are considered, but this is simply because absolute rates of activation are highly dependent on the height of the final $R_{\mathrm{d}}$ value. 
disposal between the two groups (Fig. 5). The steady state $R_{\mathrm{d}}$ values for the normal individuals during the $15-$ and $40-\mathrm{mU}$ insulin infusions thus were similar to the $R_{\mathrm{d}}$ values in the obese group at the $40-$ and $120-\mathrm{mU}$ infusions, respectively. At these comparable levels of glucose disposal, despite higher insulin infusion rates in the obese, the activation rates were still signif-

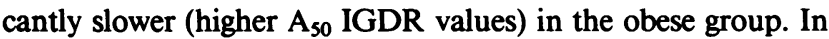
addition to reduced steady state insulin effects, insulin-resistant obese subjects thus demonstrate a striking kinetic defect in the rate of onset of insulin's stimulatory effects on glucose disposal. It should also be noted that at the pharmacologic insulin infusion rate $\left(1,200 \mathrm{mU} / \mathrm{M}^{2}\right.$ per min) extremely high plasma insulin levels $(\sim 10,000 \mu \mathrm{U} / \mathrm{ml})$ are reached within a couple of minutes. These insulin levels should rapidly saturate all plasma and tissue compartments with supraphysiologic insulin levels, and even under these conditions, activation of glucose disposal was significantly slower in the obese group. This indicates that the mechanisms underlying this defect in the rate of insulin action lie at the level of the target cell.

Although the cellular mechanisms responsible for the kinetic defects in insulin action in obesity are not elucidated by the current studies, certain inferences are possible. Decreased glucose transport activity has been described in adipocytes from insulinresistant obese subjects $(20,21)$, and the magnitude of this decrease in glucose transport activity correlates quite well to the decrease in in vivo glucose disposal (20). This suggests that a defect in the glucose transport system is responsible for the decrease in insulin's steady state effects on overall glucose disposal. Studies in adipocytes from obese animals have demonstrated a decrease in total cellular transporter number (22), consistent with the view that a decrease in transporter number exists in human obesity. A decrease in transporter number alone would not account for a slower rate of activation of insulin-stimulated glucose disposal, however, and one must postulate further abnormalities in the insulin action-glucose disposal stimulation sequence. Furthermore, this cellular defect is not common to all actions of insulin, since the rate of suppression of HGO was normal in the obese group. The cellular defect responsible for the slower rate of insulin action on glucose disposal thus most probably resides at a postbinding step and is specific for the components of the insulin action sequence that couple occupied insulin receptors to stimulation of glucose disposal.

Once the insulin infusion was discontinued, we were also able to measure the rate of deactivation of insulin's stimulatory effects on glucose disposal. Again, a striking relationship was noted between the magnitude of the insulin infusion and the fractional deactivation rate $\left(D_{50}\right.$ IGDR). As the insulin infusion rate was raised, higher $R_{\mathrm{d}}$ values were achieved, and the deactivation rates were progressively slower. In the normal subjects the $\mathrm{D}_{50}$ IGDR value thus was $34 \pm 3 \mathrm{~min}$ at the $15-\mathrm{mU}$ insulin infusion and $78 \pm 5 \mathrm{~min}$ at the $120-\mathrm{mU}$ infusion. The same relationship was noted in obesity, but for any given insulin infusion, the subsequent rate of deactivation of insulin action was faster in obesity. However, since the $R_{\mathrm{d}}$ values were directly related to the deactivation rates, and since $R_{\mathrm{d}}$ values are lower in obesity for any given insulin level, it was important to assess deactivation rates at comparable glucose disposal rates. When this was done (Fig. 5) no differences were observed in rates of deactivation of insulin action between the control and obese groups. From this we conclude that the faster deactivation rates observed in the obese group were a function of the general relationship between the height of the glucose disposal rate and the deactivation rate, and do not represent a separate intrinsic kinetic abnormality of insulin action. Even if an intrinsic defect in deactivation does not exist in obesity, the functional consequences of the general relationship between $R_{\mathrm{d}}$ and deactivation rate, plus the fact that the obese subjects achieve lower $R_{\mathrm{d}}$ values than normal for any given insulin level, means that under physiologic circumstances, deactivation of insulin's effects are faster in insulin resistant obese subjects. Furthermore, Fig. 1 shows that although they are clearly hyperinsulinemic, obese individuals do not generate sufficient hyperinsulinemia to overcome the insulin resistance and normalize glucose disposal rates; thus, insulin's effects to stimulate glucose disposal should be lower under physiologic meal eating circumstances, leading to faster rates of deactivation in this setting (23). For these reasons, it seems probable that faster deactivation is a functionally important aspect of the insulin resistance in obesity.

Integrating the kinetic and steady state results, one can see that in insulin-resistant obese subjects, for any given insulin level, the rate of onset of insulin action will be slower, the steady state effects will be less, and once the plasma hormone levels decline, dissipation of the insulin effect occurs more quickly. The slower onset and faster decay of insulin action may be particularly important functional aspects of this insulin-resistant state in view of the pulsatile manner in which insulin is normally secreted. In the physiologic setting, the hyperinsulinemia of obesity only partly compensates for these abnormalities, since slower activation of insulin action existed in obesity even when similar steady state rates of glucose disposal were achieved, and obese patients do not usually mount the three to fivefold increases in postprandial insulin secretory responses (e.g., see Fig. 1) that would be necessary to achieve glucose disposal rates reached in control subjects at normal postprandial insulin levels.

In both groups, general relationships were found between the kinetic aspects of insulin action and the ultimate magnitude of the steady state glucose disposal rate. The higher the insulin infusion rate, the greater the steady state IGDR values and the faster the rate of insulin action. The rate of deactivation of insulin's effects were slower when the steady state IGDR was higher. These findings are consistent with in vitro studies of the kinetics of insulin action (24-27), as well as the available in vivo data $(3,8,28,29)$. In vitro measurements of glucose transport in rat adipocytes (24) thus have demonstrated an inverse relationship between the height of the steady state insulin-stimulated glucose transport activity and the rate of glucose transport stimulation, such that the higher the ultimate level of glucose transport attained, the faster is the rate of activation of insulin action. Furthermore, the higher the insulin-stimulated rate of glucose transport achieved, the slower was the rate of deactivation of insulin action (25-27). The in vivo relationships demonstrated in the current studies between rate of activation, deactivation, and steady state IGDR, thus conform well to the in vitro relationships between the kinetics of insulin action on glucose transport and the steady state effects of insulin on transport stimulation. In vivo studies are also consistent with the current results. Earlier studies by Rabinowitz and Zierler (3), using the forearm perfusion technique, described a dissociation between the decay of plasma insulin and insulin's effect on forearm glucose uptake and called this phenomenon the "memory effect of insulin." Subsequent in vivo studies $(8,28,29)$ confirmed these observations showing that the decay rate of insulin in plasma was 
much more rapid than deactivation of insulin's effects on peripheral glucose uptake and suppression of HGO. Gray et al. (8) carried out studies in normal subjects, and showed that the rate of dissipation of insulin action on glucose disposal was faster when lower steady state effects of insulin were achieved.

Insulin pharmacokinetics were remarkably similar in the obese and normal groups, indicating that differences in insulin clearance, compartmentalization, or access to tissue sites of action do not explain the kinetic abnormalities of insulin's biologic effects in obesity. The half times of approach to steady state, the steady state insulin values, and the plasma insulin decay curves thus were the same between the normal and obese groups at each insulin infusion rate. These findings are in agreement with those already reported in the literature. A number of different models have been proposed to describe insulin kinetics in man (28-34). Sherwin et al. (28) proposed a three-compartment model where the plasma compartment rapidly exchanges with a liver compartment and slowly exchanges with the interstitial space. McGuire et al. did not detect differences in insulin kinetics between normal, obese, diabetic, and elderly subjects (31) using this model. Other studies in obese and normal subjects have also failed to find any alteration in the metabolic clearance rate for insulin in obesity $(1,2,35)$. Sodoyez et al. (36) and Phillipe et al. (37) used an in vivo approach to study the relationship between plasma insulin and the kinetics of insulin binding and dissociation and found extremely close temporal relationships with only a 1-2-min lag period between insulin turnover in plasma, and turnover at tissue receptor sites. A slower rate of onset of insulin action in the current studies was observed in the obese subjects even at suprasaturating insulin levels (Figs. 3 and 4). Taken together, these findings argue that the kinetic defects in insulin action observed in the present study are not related to insulin pharmacokinetics or the kinetics of insulin binding to target tissue receptors.

The effects of insulin to suppress HGO are clearly decreased in obesity, but several important differences exist between resistance to insulin's hepatic effects compared with the resistance to insulin stimulation of peripheral glucose disposal. Although the steady state effects of insulin to suppress HGO are less in obesity, these differences are only seen at submaximal insulin levels, and the magnitude of this defect is relatively modest compared to the decrease in insulin-stimulated glucose disposal. Since $100 \%$ suppression of HGO is seen in both groups at higher insulin levels ( $\geq 100 \mu \mathrm{U} / \mathrm{ml}$ in normals and $\geq 300 \mu \mathrm{U} / \mathrm{ml}$ in obese), the hepatic insulin resistance in obesity is manifested only by decreased insulin sensitivity, whereas the peripheral defect involves both decreased sensitivity and decreased maximal responsiveness. At all insulin levels, the rate of suppression of HGO was faster than stimulation of glucose disposal in both groups. Furthermore, in constrast to stimulation of glucose disposal, the rate of suppression of HGO by insulin was normal in obesity. The hepatic insulin resistance in obesity (decreased insulin sensitivity with normal rate of onset of insulin action) thus is compatible with the decrease in insulin receptors, particularly liver membrane receptors (38), which have been reported in human obesity. In contrast, the resistance to insulin-stimulated glucose disposal involves decreased insulin sensitivity, decreased maximal responsiveness, and a slower rate of activation of insulin action; this is best explained by decreased insulin receptors, and more importantly, by decreased insulin action at a postbinding step.
Of interest is the finding that the rate of recovery of HGO from insulin's suppressive effects is more rapid in obesity and, in view of the phasic manner in which insulin is normally secreted, this could have considerable functional significance in terms of altered glucose tolerance. It is tempting to speculate that the reduced glucagon suppression and more rapid return of glucagon to basal levels mediates the rapid recovery of HGO after the insulin infusions were stopped. Indeed the basal hyperglucagonemia and relatively impaired suppression of glucagon levels by the insulin infusions in obesity may contribute to all of the aspects of hepatic insulin resistance in this condition. Taken together, the present results show that in obesity, resistance to insulin suppression of $\mathrm{HGO}$ is quantitatively mild compared to peripheral insulin resistance. Additionally, qualitative differences exist suggesting that decreased insulin receptors and relative hyperglucagonemia underlie the hepatic insulin resistance, whereas decreased insulin receptors plus postbinding defects in insulin action cause the peripheral insulin resistance.

In summary, the current studies demonstrate new aspects of the insulin-resistant state in human obesity. The data show that not only are the steady state effects of insulin reduced in obesity, but there are also marked kinetic alterations in the rates of insulin action to stimulate glucose disposal and suppress HGO. Since insulin is normally secreted in a phasic manner and steady state biologic effects of this hormone are probably not achieved under physiologic circumstances, we postulate that these kinetic abnormalities of insulin action in insulin-resistant obese subjects, represent a functionally important aspect of the insulin resistance, and may be the dominant manifestation of the insulin resistance in the physiologic, meal eating state.

\section{Acknowledgments}

The authors wish to thank P. Elliot, T. Morrison, and R. Thorne for their skilled technical assistance, Paul Shragg for his advice in the statistical analysis of the data, and Cleon Tate and Elizabeth Martinez for their expert secretarial assistance.

This work was supported in part by grants AM 33649 from the National Institutes of Health and from the Medical Research Service of the Veterans Administration Medical Center. Dr. Prager is a recipient of a Max Kade Foundation Postdoctoral Fellowship Award.

\section{References}

1. Kolterman, O. G., J. Insel, M. Saekow, and J. M. Olefsky. 1980. Mechanisms of insulin resistance in human obesity. Evidence for receptor and postreceptor defects. J. Clin. Invest. 65:1272-1284.

2. De Fronzo, R. A., V. Soman, R. J. Sherwin, R. Hendler, and P. Felig. 1978. Insulin binding to monocytes and insulin action in human obesity, starvation and refeeding. J. Clin. Invest. 61:209-213.

3. Rabinowitz, P., and K. L. Zierler. 1962. Forearm metabolism in obesity and its response to intraarterial insulin. J. Clin. Invest. 41:21732181 .

4. Perley, M., and D. Kipnis. 1966. Plasma insulin response to glucose and tolbutamide of normal weight and obese diabetic and nondiabetic subjects. Diabetes. 15:867-874.

5. Kolterman, O. G., G. M. Reaven, and J. M. Olefsky. 1979. Relationship between in vivo insulin resistance and decreased insulin receptors in obese man. J. Clin. Endocrinol. Metab. 48:487-494.

6. Olefsky, J. M. 1981. Insulin resistance and insulin action: An in vitro and in vivo perspective. Diabetes. 30:148-162.

7. De Fronzo, R. A., J. D. Tobin, and R. Andres. 1979. Glucose clamp technique. A method for quantifying insulin secretion and resistance. Am. J. Physiol. 273:E214-E223. 
8. Gray, R. S., J. A. Scarlett, J. Griffin, J. M. Olefsky, and O. G. Kolterman. 1982. In vivo deactivation of peripheral, hepatic and pancreatic insulin action in man. Diabetes. 31:929-936.

9. Steele, R. 1958. Influence of glucose loading and injected insulin on hepatic glucose output. Ann. NY Acad. Sci. 82:420-430.

10. Desbuquois, B., and G. D. Aurbach. 1971. Use of polyethylene glycol to separate free and antibody bound peptide hormones in radioimmunoassay. J. Clin. Endocrinol. Metab. 33:732-738.

11. Unger, R. H., and G. R. Faloona. 1979. In Methods of Hormone Radioimmunoassay. B. M. Jaffe, H. R. Behrman, editors. Academic Press, New York. 18:317-330.

12. Finegood, D. T., and R. N. Bergman. 1983. Optimal segments: a method for smoothing tracer data to calculate metabolic fluxes. $\mathrm{Am}$. J. Physiol. 244:E472-E479.

13. National Diabetes Data Group. 1979. Classification and diagnosis of diabetes mellitus and other categories of glucose intolerance. Diabetes. 28:1039-1057.

14. Reaven, G. M., R. Bernstein, B. Davis, and J. M. Olefsky. 1976. Nonketotic diabetes mellitus: Insulin deficiency or insulin resistance. Am. J. Med. 60:80-88.

15. Beck-Nielsen, H. 1978. The pathogenic role of an insulin receptor defect in diabetes mellitus of the obese. Diabetes. 27:1175-1181.

16. Kolterman, O. G., R. S. Gray, J. Griffin, J. Burstein, J. Insel, J. A. Scarlett, and J. M. Olefsky. 1981. Receptor and postreceptor defects contribute to the insulin resistance in non-insulin-dependent diabetes mellitus. J. Clin. Invest. 68:957-969.

17. De Fronzo, R. A., D. Deibert, R. Hendler, P. Felig, and V. Soman. 1979. Insulin sensitivity and insulin binding to monocytes in maturity onset diabetes. J. Clin. Invest. 63:939-946.

18. Baron, A. D., O. G. Kolterman, J. Bell, L. J. Mandarino, and J. M. Olefsky. 1985. Rates of non-insulin mediated glucose uptake are elevated in Type II diabetic subjects. J. Clin. Invest. 76:1782-1788.

19. Kahn, C. R. 1978. Insulin resistance, insulin insensitivity and insulin unresponsiveness. A necessary distinction. Metab. Clin. Exp. 27(Suppl. 2):1893-1902.

20. Ciaraldi, T. P., O. G. Kolterman, and J. M. Olefsky. 1981. Mechanism of the postreceptor defect in insulin action in human obesity. Decrease in glucose transport system activity. J. Clin. Invest. 68:875880.

21. Pedersen, O., E. Hjollund, and N. S. Sorensen. 1982. Insulin receptor binding and insulin action in human fat cells. Effects of obesity and fasting. Metab. (Clin. Exp.). 31:889-895.

22. Hissin, P. J., J. E. Foley, L. J. Wardzala, E. Karnieli, I. A. Simpson, L. B. Salans, and S. W. Cushman. 1982. Mechanisms of insulin-resistan glucose transport activity in the enlarged cell of the aged, obese rat. Relative depletion of intracellular glucose transport systems. J. Clin. Invest. 70:780-790.

23. Prager, R., P. Wallace, and J. M. Olefsky. 1986. The postprandial hyperinsulinemia of obesity does not compensate for insulin resistance. Clin. Res. 34:064A.

24. Ciaraldi, T. P., and J. M. Olefsky. 1982. Kinetic relationship between insulin receptor binding and effects on glucose transport in rat adipocytes. Biochemistry. 21:3475-3480.

25. Haring, H. U., E. Bierman, and W. Kemmler. 1982. Relation of insulin receptor occupancy and deactivation of glucose transport. Am. J. Physiol. 292:E239-E240.

26. Ciaraldi, T. P., and J. M. Olefsky. 1980. Relationship between deactivation of insulin stimulated glucose transport and insulin dissociation in isolated rat adipocytes. J. Biol. Chem. 255:327-334.

27. Ciaraldi, T. P., and J. M. Olefsky. 1983. Length of acute exposure to insulin regulates the rate of deactivation of stimulated glucose transport in isolated rat adipocytes. Endocrinology. 113:1739-1745.

28. Sherwin, R. S., K. J. Kramer, J. D. Tobin, P. A. Insel, J. E. Liljenquist, M. Berman, and R. Andres. 1974. A model of the kinetics of insulin in man. J. Clin. Invest. 53:1481-1482.

29. Insel, P. A., J. E. Liljenquist, J. D. Tobin, R. S. Sherwin, P. Watkins, R. Andres, and M. Berman. 1975. Insulin control of glucose metabolism in man. J. Clin. Invest. 55:1057-1066.

30. Eaton, R. P., R. C. Allen, D. S. Schade, K. M. Erickson, and J. Standefer. 1980. Prehepatic insulin production in man: kinetic analysis using peripheral connecting peptide behavior. J. Clin. Endocrin. Metab. 51:520-528.

31. McGuire, E. A., J. D. Tobin, M. Berman, and R. Andres. 1979. Kinetics of native insulin in diabetic, obese and aged men. Diabetes. 28 : 110-120.

32. Tranberg, K. G., and H. Dencker. 1978. Model of plasma disappearance of unlabeled insulin in man. Am. J. Physiol. 235:E577-E585.

33. Toffolo, G., R. N. Bergman, D. T. Finegood, C. R. Bowden, and C. Cobelli. 1980. Quantitative estimation of beta cell sensitivity to glucose in the intact organism. A minimal model of insulin kinetics in the dog. Diabetes. 29:979-990.

34. Silvers, A., R. S. Swenson, J. W. Farquhar, and G. M. Reaven. 1969. Derivation of a three compartment model describing disappearance of plasma insulin ${ }^{131} \mathrm{~J}$ in man. J. Clin. Invest. 48:1461-1469.

35. Bogardus, C., S. Lillioja, D. M. Mott, C. Hollenbeck, and G. Reaven. 1985. Relationship between the degree of obesity and in vivo insulin action in man. Am. J. Physiol. 248:E286-E291.

36. Sodoyez, T., F. R. Sodoyez-Goffaux, and Y. M. Moris. 1980 ${ }^{125} \mathrm{I}$-Insulin kinetics of interaction with its receptors and rate of degradation in vivo. Am. J. Physiol. 239:E3-E11.

37. Phillippe, J., A. Phillippe, A. Halban, and A. Gjinvoci. 1981. Increased clearance and degradation of $\left[{ }^{3} \mathrm{H}\right]$ Insulin in streptozotocin diabetic rats. Role of the insulin-receptor compartment. J. Clin. Invest. 67:673-680

38. Arner, P., K. Einarsson, L. Backman, K. Nilsell, K. M. Lerea, and J. N. Livingston. 1983. Studies on liver insulin receptors in nonobese and obese human subjects. J. Clin. Invest. 72:1729-1736. 